\title{
Território e saúde mental: contribuições conceituais da geografia para o campo psicossocial
}

\author{
Territory and mental health: conceptual contributions of geography to the psychosocial field \\ Territorio y salud mental: contribuciones conceptuales de la geografía para el campo \\ psicosocial
}

\author{
Aline Basso da Silva ; Leandro Barbosa de Pinho
}

\begin{abstract}
RESUMO: Este artigo tem como tema o território e saúde mental e discute as contribuições da geografia para o campo psicossocial, pensando o território como o local de cuidado em saúde mental. Historiciza brevemente a ideologia psiquiátrica da produção do comum nos hospícios, apresentando a necessidade de se pensar alternativas de cuidado que reforcem as singularidades dos sujeitos e fora dos muros dos manicômios. Desenvolve o tema do território como local de potência para o cuidado e foco da desinstitucionalização, aproximando-se da geografia para analisar o espaço de atuação da vida humana. Encerra com a discussão conceitual do território embasada em autores do campo conceitual da Geografia, e suas interfaces com a prática no contexto da atenção psicossocial. Por fim, a proposta é apoiar-se na interdisciplinaridade para ampliar o debate da desinstitucionalização da loucura.

Palavras-Chave: Saúde mental; desinstitucionalização; enfermagem; geografia.
\end{abstract}

\begin{abstract}
The subject of this article is the territory and mental health. It discusses the contributions of geography to the psychosocial field, considering the territory as the place of mental health care. It briefly historicizes the psychiatric ideology of production of the common in hospices, presenting the need to think about care alternatives that reinforce the uniqueness of individuals and occur outside the walls of asylums. It develops the theme of the territory as a potent place for a deinstitutionalized care and focus, approaching Geography to analyze the space where human life is acted out. It concludes with a conceptual discussion of territory, based on authors from the conceptual field of Geography, and its interfaces with practice in the psychosocial care context. Lastly, the proposal is to rely on interdisciplinarity to enlarge the discussion of the deinstitutionalization of madness.

Keywords: Mental health; deinstitutionalization; nursing; geography.

RESUMEN: El tema de este artículo es el territorio y la salud mental. Su objetivo es debatir las contribuciones de la geografía para el campo psicosocial, interpretando al territorio como escenario de cuidado en salud mental. Narra brevemente la ideología psiquiátrica de la producción de lo común en los hospitales psiquiátricos y presenta la necesidad de pensar en alternativas de cuidado para reforzar las singularidades de las personas, fuera de esos espacios. Desarrolla el tema del territorio como sitio de potencia para el cuidado y foco de la desinstitucionalización, acercándose a la geografía para analizar el espacio de actuación de la vida humana. Termina con la discusión conceptual del territorio basada en autores del campo conceptual de la geografía y sus relaciones con la práctica en el contexto de la atención psicosocial. En suma, la propuesta es apoyarse en la interdiciplinariedad para ampliar el debate de la desinstitucionalización de la locura.

Palabras Clave: Salud mental; desinstitucionalización; enfermería; geografía.
\end{abstract}

\section{INTRODUÇÃO}

As raízes que sustentaram o hospício, como cenário de tratamento do louco durante séculos, perduram até hoje. A ideologia psiquiátrica tradicional, nascida nesses espaços, foi importante como movimento que buscou uma nova compreensão para algo ainda incompreendido. No entanto, não totaliza a loucura como extensão da vida humana, uma vez que é complexa e multidimensional.

Elevada à categoria de doença pela medicina mental, com inspiração cartesiana, a loucura entrou no rol das patologias das quais era necessário encontrar as causas e os desfechos. Com Pinel, Esquirol, Falret e Morel, desenvolveram-se novas explicações que demonstravam a racionalidade sobre o conhecimento da loucura, superando as concepções empiristas e fundando uma nova clínica ${ }^{1}$. É nesse sentido que novos espaços devem ser criados para compreender fatos e processos inerentes à doença ${ }^{2}$.

A partir da Segunda Guerra Mundial, o questionamento do papel terapêutico do hospício torna-se acirrado, denotando local de opressão, exclusão social e denegação das singularidades. Além de ser um local

IDoutoranda em Enfermagem pela Universidade Federal do Rio Grande do Sul. Porto Alegre, Rio Grande do Sul, Brasil. E-mail alinee basso@ 0 hotmail.com. IIDocente permanente da Universidade Federal do Rio Grande do Sul. Porto Alegre, Rio Grande do Sul, Barsil. Email: lbpinho@uol.com.br 
que produz mortificação pela absorção da totalidade do indivíduo, o hospício não parece revelar e compreender a diferença, produzindo o comum, o doente ${ }^{3}$.

A (in)percepção da loucura como algo próprio da natureza humana parece revelar ainda a ignorância sobre o assunto. Reduzir a complexidade das singularidades humanas à racionalidade da doença parece uma explicação consistente para a clínica, no entanto, equivocada quando enxergamos as diferenças que tornam as pessoas singulares. Além da desconstrução dessa imagem perversa sobre o sujeito, é necessário demolir os muros do manicômio que nos isolam do contato com a loucura ${ }^{4}$.

A verdadeira desinstitucionalização valoriza a diversidade e os encontros. E se no manicômio, com suas atitudes antiterapêuticas, isso não é possível, é preciso potencializar novos espaços e cenários que registrem a vida real das pessoas e que absorvam suas singularidades. É, portanto, no território que podemos exercer novas práticas de cuidado. Isso porque já conhecemos a clínica da loucura, mas procuramos agora conhecer a nova clínica, que invista na singularidade e na construção de projetos interdisciplinares, produzindo novos conhecimentos teóricos na área e competências técnicas com os trabalhadores. Assim, o objetivo deste estudo foi refletir sobre as contribuições da geografia para enriquecer o debate sobre o campo psicossocial.

Trata-se de um estudo teórico, reflexivo, que investe numa amarração interdisciplinar ao debater a articulação do conceito de território, do ponto de vista da geografia, e suas respectivas aplicações ao campo da saúde mental.

\section{Território e Saúde Mental}

Pensar no território como cenário de cuidado é, antes disso, entender que a psiquiatria tradicional precisava ser reformada. Em países como Inglaterra, França, EUA e Itália, essas discussões foram mais aprofundadas. Neles, surgiram experiências inovadoras de transformação da assistência psiquiátrica que resultaram em propostas de base comunitárias, responsáveis pela ressignificação do cuidado psiquiátrico centrado no hospital e pelo investimento no território como cenário ideal para esse cuidado 5 .

A Itália foi o local em que essas transformações puderam ser sentidas com maior intensidade. Houve fechamento gradual e planejado dos hospitais psiquiátricos em funcionamento, constituição de serviços de pronto-atendimento psiquiátricos na comunidade, restrição às internações compulsórias e incentivo à construção de serviços substitutivos, na comunidade, baseados no princípio da territorialidade ${ }^{6}$.

Nesse processo, o território é o principal local de cuidado, fugindo dos discursos homogeneizantes da ideologia psiquiátrica tradicional. É nele que se constrói toda a história da sociedade, os processos políticos, econômicos e sociais, as lutas e disputas, os conflitos e as relações. Nesses espaços, as famílias vivem e se organizam e, para eles, é preciso repensar projetos que potencializem o convívio entre os diferentes e o cuidado para aqueles que precisam.

Ainda notamos a necessidade de superação do hospício, muito embora já se tenha avançado para além de seus muros; entretanto, este tipo de instituição continua presente no imaginário e na cultura da sociedade. Por isso, a desinstitucionalização deve ser vista como processo que se inicia, mas que não termina, numa dialética de ir-e-vir.

Uma dessas alternativas extra-hospitalares substitutivas ao manicômio e que funcionam no território são os Centros de Atenção Psicossocial (CAPS). São dispositivos estratégicos no processo de consolidação da reforma psiquiátrica, mas que não totalizam o cuidado ao indivíduo. Isso porque ele deve atuar em rede, considerando que a integralidade do sujeito e a compreensão da loucura prescindem de vários olhares. Desse modo, o CAPS deve atuar em parcerias com outros dispositivos da rede?

Quando se discute rede de serviços, dispositivos e locais de cuidado dispostos no território aborda-se bem mais do que um mapeamento físico de uma comunidade a qual precisamos atender. Constitui-se um novo conceito de saúde mental, marcado pelo espaço em que a vida acontece e se processa, cada uma com suas características e peculiaridades.

Cada território é um território; então, nota-se a necessidade de suporte teórico interdisciplinar para melhor compreender sua importância na discussão do cuidado em saúde mental. Em se tratando de um cenário espacial, mas também geopolítico, é na geografia que se pode encontrar melhores sustentações ${ }^{8-10}$.

Perceber e incorporar este território que transcende o físico é essencial para avançarmos na constituição de políticas públicas em saúde mental. Território é o lugar de potência, marcado por relações de poder, relações sociais, de luta e história.

\section{Prosseguindo o Debate}

A expansão da informação e a constituição de redes voltadas para o cuidado em saúde no contexto do Sistema Único de Saúde (SUS) perpassam a organização dos fluxos no território. Por isso, entendemos que nossa aproximação com a geografia, como ciência que interpreta e analisa o espaço de atuação da vida humana, pode ser uma contribuição substantiva para problematizar o cuidado em saúde mental nos espaços comunitários.

Historicamente, a geografia articula com a área da saúde a partir da globalização e dos problemas ambientais, gerando amplas discussões internacionais que prescindem a dinâmica do mundo em rede que trouxe 
reflexões sobre o papel do espaço geográfico, a possibilidade de fluxos muito rápidos de vírus e bactérias e a disseminação de epidemias ${ }^{11}$.

Conhecido como separado do campo e das pessoas, o espaço geográfico predispõe a ocorrência de doenças. No entanto, a partir da teoria do parasitologista Pavlovsky, denominada Epidemiologia Paisagística, é que se pensa uma nova relação entre espaço/ doença pela ideia da circulação dos agentes ${ }^{12}$.

Com a Epidemiologia Paisagística, o espaço passa a ser visto como interdependente, ou seja, produto e produtor das relações. No entanto, havia uma crítica à insuficiência desse modelo de análise nas doenças não transmissíveis, despontando em visualidade as teorias de multicausalidade e o conceito de risco ${ }^{13}$. Na Teoria da Multicausalidade, as populações humanas são secundarizadas, nas quais o foco é no comportamento como principal fator que leva as pessoas a adoecerem e morrerem ${ }^{13}$.

Nesse sentido, é na década de 1970, com a configuração firme de uma nova sociedade globalizada, que foi lançado um movimento criticando a epidemiologia dos fatores de risco e as concepções ecológicas de doença. Esse movimento ficou conhecido como epidemiologia social ou epidemiologia crítica, com grande repercussão na América Latina ${ }^{12}$.

Nota-se maior fortalecimento da categoria espaço em estudos da saúde pública, não só pela mudança no perfil de morbimortalidade, passando de causas infecciosas para doenças crônico-degenerativas, mas também pelo crescimento da Síndrome da Imunodeficiência Adquirida na população. Era necessário conhecer melhor os coletivos. Nessa perspectiva, a geografia torna-se uma aliada potente da saúde, por estar intimamente ligada ao objeto espaço geográfico ${ }^{14}$.

No Brasil, Milton Santos apresenta-se como o principal autor na difusão do conceito de espaço geográfico ou socialmente organizado que trouxe ao olhar dos sanitaristas uma reorientação aos seus trabalhos, considerando o espaço como um processo, uma construção social, ou seja, o espaço é vivo e pode ser vivido ${ }^{12}$.

Nesse sentido, compreendemos que a historicização do conceito de espaço permitiu ressignificar o olhar sobre o processo saúde/doença refletindo sobre experiências que reforçam que saúde e doença dependem de múltiplas dimensões sociais.

Diferente do espaço, o conceito de território surgiu com a Reforma Sanitária e com a implantação do SUS, nos quais o território se estrutura como área político-administrativa, sendo uma repartição dos espaços e dos processos que o desenvolvem ${ }^{12}$.

Formado a partir de um dado espaço, o território fica marcado por uma projeção de trabalho e poder e pelos modos de produção. Por exemplo, temos o ter- ritório nacional como espaço físico de uma nação, o qual delimita uma ordem político-administrativa, um espaço medido e marcado pelo trabalho humano. $\mathrm{O}$ espaço é territorializado pelo ator, mostrando que o território se apoia no espaço, mas não o é 9 .

Essa concepção ajuda a sustentar certa organização do sistema de saúde brasileiro. Nesse caso, a delimitação espacial do campo de abordagem da saúde é aplicada a diversos serviços do SUS, como a estratégia saúde da família, os programas de vigilância em saúde e na saúde mental, por meio dos Centros de Atenção Psicossocial (CAPS). No entanto, apesar de potencializar e facilitar a gestão do espaço pelos serviços locais, essa estratégia pode reduzir o conceito de espaço somente a uma questão de modernização político-administrativa, enfraquecendo o potencial do conceito de território para a compreensão das singularidades das populações e dos problemas de saúde de determinada área ${ }^{15}$.

Além de uma questão político-administrativa, o objetivo é conhecer este território delimitado para que, assim, seja possível conhecer a vida das populações. Então, ele é o território da organização das práticas de saúde, suporte dos serviços, suporte da vida das populações, da conformação dos contextos que explicam a produção dos problemas de saúde e bem-estar ${ }^{16}$.

No território da saúde, é preciso compreender as várias características físicas de uma área, mas também as marcas produzidas pelo homem, suas relações sociais, a forma com que se organizam e transitam por esse território. Há uma inseparabilidade estrutural, funcional e processual entre a sociedade e o espaço geográfico, e isso o homem precisa conhecer ${ }^{10}$.

Consideramos que o território perpassa a soma de experiências inovadoras no campo da gestão administrativa dos serviços, bem como na gestão dos processos da vida cotidiana. Isto porque não é possível buscarmos a reorganização político-técnica dos serviços sem considerarmos a existência da vida humana, sua história e organização política e social.

Diante disso, compreendemos o território como um importante locus de cuidado em saúde mental e um poderoso componente para análise e planejamento das ações em saúde. A dimensão que o espaço recebe para contemplar as questões relacionais, socioculturais e políticas daquela sociedade vai configurando outro território, ou seja, marcando-o como um território dinâmico, ativo e polivalente.

Nessa perspectiva, quando quisermos definir qualquer pedaço de território, devemos levar em conta a interdependência e a inseparabilidade entre a materialidade, que inclui a natureza, e o seu uso, que inclui a ação humana, ou seja, o trabalho e a política. Portanto, o território é um recorte ou fração do espaço qualificado pelo sujeito, um território usado, pois é o espaço vivido pelo homem ${ }^{17}$. 
Assim, visualizamos contribuições teóricas que sustentam o território como espaço de trocas e relações sociais, perpassadas pelas características econômicas, políticas e locorregionais. Ao analisá-lo, é preciso observar as características elementares dos sujeitos que neles habitam e admitir que o território é qualificado pela vida das pessoas e suas relações construídas ao longo do tempo.

É nessa linha de raciocínio que se acredita que o território esteja ligado ao poder e às relações sociais. No entanto, vai-se além dessa compreensão, considerando o território como pleno de autonomia e de descontinuidades, além de formado por redes de grupos organizados em vários horários e turnos ${ }^{10}$.

Os territórios podem ser formados e dissipados de modo rápido, mais instáveis que estáveis. Entre esses territórios flexíveis, por exemplo, destacam-se os territórios de prostituição, em que grupos específicos se apropriam do território durante a noite, enquanto diurnamente são ocupados por outras pessoas, pelo comércio e por moradores da região. Outro seria o território do tráfico de drogas, cuja territorialidade demonstra certa estrutura característica de organizações mafiosas, onde teríamos os territórios amigos e os inimigos. Uma territorialidade complexa, unida pelo pertencimento ao mesmo comando, sendo que, nesse espaço concreto, os nós se intercalam com nós de outras redes, todas elas superpostas no mesmo espaço e disputando uma mesma área ${ }^{10}$.

Assim, o conceito de territorialidade nos ajuda a compreender o processo de constituição dos territórios. É um tipo de interação entre os seres humanos, mediadas pelo espaço. Esta ideia é relevante no debate do cuidado em saúde mental, pois é nos espaços da saúde, como serviços e dispositivos da rede, que o ator territorializa o lugar com suas ações, fazendo parte do processo de constituição do território e da rede ${ }^{10}$.

Nesse contexto, cita-se o trabalhador da saúde que, ao incorporar-se ao espaço da rede de serviços e da comunidade, começa a fazer parte do território de forma descontínua, estando naquele espaço em determinados dias e horas da semana, mas fazendo parte da constituição cultural, econômica e social do lugar, contribuindo para a re(constituição) daquele espaço.

Um dos conceitos pertinentes no debate do território na saúde mental é o conceito de território-rede, que é trazido como o território descontínuo ${ }^{10}$. É uma rede que articula dois ou mais territórios contínuos. A complexidade do território-rede remete à superação da concepção clássica de território, observando-se a superposição de vários deles, com formas variadas e limites não coincidentes. Neles, pode haver diversas territorialidades que se complementam ou se contradizem, dando um caráter de diferentes relações de poder e movimento.

O território-rede é um conceito relevante na compreensão do território na saúde mental. Isso quer dizer que esse cuidado se distribui nos territórios de vida das pessoas, formando redes de universos complexos e paralelos, mediados pelas tendências modernas de gestão do espaço, com as características locais e necessidades singulares da população.

Percebemos a importância de os serviços de saúde pensarem e repensarem suas práticas, compreendendo que o cuidado deve avançar para fora dos serviços, visando à desinstitucionalização da loucura. A desinstitucionalização envolve políticas que olhem para os aspectos subjetivos, a condição de cidadania e liberdade, com o intuito de retomar a sociabilidade do usuário $^{18}$. Dessa forma, conceitos da geografia contemporânea ajudam reconhecer que o território também é marcado pela presença do humano e de sua ação. Acreditamos que, desse modo, a prática em saúde mental fica mais sofisticada e focada no cuidado em liberdade, no respeito às singularidades e nas trocas, premissas fundamentais do modo psicossocial e da reforma psiquiátrica.

\section{Conclusão}

Pensar no território e numa rede para fora dos serviços é criar meios para desinstitucionalizar o cuidado às pessoas, reconhecendo suas singularidades e complexidades, pois, nesse contexto, está inserida a existência das diversidades e heterogeneidades dos sujeitos. Cada sujeito possui um território, carregado de história, relações de poder, relações sociais, formas de organização e economia. O território é autônomo e possui movimento, marcado por transformações advindas dessa organização histórica e social das populações.

Esperamos que este estudo fomente contribuições interdisciplinares para ampliarmos as discussões sobre o tema do território na saúde mental, articulando com outras áreas do saber, como a geografia, para que, assim, avancemos no debate da desistitucionalização da loucura.

Trabalhar com o território é apostar na criação de alternativas de cuidado. Olhar para os lugares onde as pessoas vivem e se relacionam e o quanto estes lugares mostram suas singularidades, diversidades e realidades, concepções essenciais para o cuidado no campo psicossocial.

\section{REFERÊNCIAS}

1.Pessotti I. A loucura e as épocas. Rio de Janeiro: Editora 34; 1994.

2.Birman J. A psiquiatria como discurso da moralidade. Rio de Janeiro: Edições Graal; 1978.

3.Goffman E. Manicômios, prisões e conventos. $3^{\mathrm{a}} \mathrm{ed}$. São Paulo: Perspectiva; 1990.

4.Pelbart P. Da clausura do fora ao fora da clausura. São Paulo: Brasiliense; 2001. 
5.Basaglia F. A instituição negada. $3^{\mathrm{a}}$ ed. Rio de Janeiro: Graal; 2001.

6.Ongaro Basaglia F. Saúde/doença. In: Amarante PDC, Cruz LB, organizadores. Saúde mental, formação e crítica. Rio de Janeiro: Laps; 2008. p.17-50.

7.Delgado PGG. Democracia e reforma psiquiátrica no Brasil. Ciênc saúde coletiva. 2011. [citado em 14 jul 2014]; 16:4701-6. Disponível em: http://www.scielo.br/ pdf/csc/v16n12/19.pdf.

8.Santos M. Por uma outra globalização: do pensamento único à consciência universal. Rio de Janeiro: Record; 2003. 9.Raffestin C. Por uma geografia do poder. São Paulo: Ática; 1993.

10.Souza MJL. O território: sobre espaço e poder. In: Castro IE, Gomes PCC, Corrêa RL, organizadores. Geografia: conceitos e temas. Rio de Janeiro: Bertrand Brasil; 2001.p. 78-113.

11.Castells M. A sociedade em rede. $6^{\mathrm{a}}$ ed. São Paulo: Paz e Terra; 2002.

12. Monken M, Peiter P, Barcellos C, Rojas LIR, Navarro M, Gondim GMM, et al. O território na saúde: construindo referências para análises em saúde e ambiente. In: Barcellos C, Miranda AC, Moreira JC, Monken M, organizadores. Território, ambiente e saúde. Rio de Janeiro: Fiocruz; 2008.p. 23-41.
13.Castellanos PL. Epidemiologia, saúde pública, situação de saúde e condições de vida: considerações conceituais. In: Barradas RB, organizador. Condições de vida e situações de saúde. Rio de Janeiro: Abrasco; 1997.

14.Czeresnia D, Ribeiro AM. O Conceito de espaço em epidemiologia: uma interpretação histórica e epistemológica. Cad Saúde Pública. 2000 [citado em 30 jun 2014]; 16:595-613. Disponível em: http://www.scielosp. org/pdf/csp/v16n3/2947a.

15.Monken M, Barcellos C. Vigilância em saúde e território utilizado: possibilidades teóricas e metodológicas. Cad Saúde Pública. 2005 [citado em 28 jul 2014]; 21:898-906. Disponível em: http://www.scielo.br/pdf/ csp/v21n3/24.pdf.

16. Unglert CVS. Territorialização em sistemas de saúde. In: Mendes EV, organizadores. Distritos sanitários: processo social de mudança nas práticas sanitárias para o Sistema Único de Saúde. São Paulo: Hucitec; 1993.p.221-35.

17.Santos M, Silveira ML. O Brasil: território e sociedade no início do século XXI. 9ª ed. São Paulo: Cortez; 2011. 18.Dultra RFD, Rocha RMR. O processo de desinstitucionalização psiquiátrica: subsídios para o cuidado integral. Rev enferm UERJ. 2011; 19:386-91. 